\title{
Religion and spirituality in contemporary dreams
}

\author{
Author: \\ Werner Nell ${ }^{1}$ \\ Affiliation: \\ ${ }^{1}$ School of Behavioural \\ Sciences, North-West \\ University, Vaal Triangle \\ Campus, South Africa \\ Correspondence to: \\ Werner Nell \\ Email: \\ werner.nell@nwu.ac.za \\ Postal address: \\ PO Box 1174, Vanderbijlpark \\ 1911, South Africa \\ Dates: \\ Received: 25 Feb 2011 \\ Accepted: 10 May 2011 \\ Published: 20 Feb. 2012 \\ How to cite this article: \\ Nell, W., 2012, 'Religion and \\ spirituality in contemporary \\ dreams', HTS Teologiese \\ Studies/Theological Studies \\ 68(1), Art. \#1039, 9 pages. \\ http://dx.doi.org/10.4102/ \\ hts.v68i1.1039
}

(C) 2012. The Authors. Licensee: AOSIS OpenJournals. This work is licensed under the Creative Commons Attribution License.
This article examines the spiritual value and role of dreams in the lives of South African Christians, based on the findings of a qualitative research project in which semistructured interviews were used to examine the dream-related beliefs and practices of contemporary Christians. The findings indicated that dreams are still considered to be of distinct religious value and importance by a significant number of the Christian participants who took part in the study. Specifically, the participants reported that their dreams often serve as source of spiritual inspiration, insight and guidance, as well as feedback on decisions and ways of living. It was also indicated that dreams sometimes constituted an important natural resource in coming to terms with bereavement. In response to this, the article closes with a call for a re-evaluation of the position and value of dreams in contemporary Christianity, and offers several practical suggestions for working with dreams in a spiritual context.

\section{Introduction}

Does God still speak to his followers through dreams? Dreams have been a topic of significant focus in Christianity for many centuries. In addition to constituting an essential component of many biblical narratives, early Christian scholars often devoted extensive attention to the subject of dreams in the context of religion, as will be discussed later. In stark contrast, contemporary scholars focusing on the study of Christianity have generally paid little or no attention to dream research (Bulkeley 2009:30). Amongst the few studies that have been conducted to examine the role played by religion in contemporary dreams, the majority were conducted either within the contextual framework of existing psychological dream theories such as those of Sigmund Freud and Carl Jung (e.g. Eliade 1964; Kripal 1995, 2001), or within the context of spirituality in general, and focused on dream content, rather than on dream related beliefs (e.g. Bulkeley 2009; Casto 1995). Hall (1997) supports this contention in an even broader context when he states that in spite of there being a wealth of historical, anthropological and psychological literature on the many types of dreams and dreaming there has been scant research on what people think and believe about dreams. More specifically, no contemporary research whatsoever could be located that investigates what roles dreams might play in the religious experience of the average South African Christian, based on their own attitudes, beliefs and perceptions of the religious and spiritual value of their dreams.

To address this gap in contemporary dream research, the researcher examined the dream-related beliefs, attitudes and practices of a purposively selected group of participants via semi-structured qualitative interviews. Approaching the study from the perspective of existing psychological dream theories was purposefully avoided during this process in order to prevent tainting the findings with the assumptions underlying such theories. During the interviews, participants were directly questioned about their views on various aspects of their dreams with regard to nine general themes identified via an extensive literature review. As will be discussed in a subsequent section, two of these themes had direct relevance to the perceived spiritual aspects of dreams. Whilst not initially a research criterion, all the participants identified themselves as Christians, and the answers received by the participants would therefore be especially relevant in this particular context. The data obtained from the interviews were subject to qualitative content and discourse analysis, and the findings revealed that many of the participants viewed at least some of their dreams in a spiritual light. In presenting these findings, the article concludes that at least some people who consider themselves Christians do still attach significant spiritual value to their dreams, and also discusses the specific ways in which this value was perceived by the participants. The article closes with a reflection on the potential religious value of dreams and calls for a respiritualising and reincorporation of dreams within contemporary Christian contexts.

\section{The role of dreams in historical Christianity The dream in biblical times}

An overview of literature on the historical aspects of dreams in various cultural contexts clearly reveals that these nightly phenomena were often imbued with substantial religious and spiritual 
significance and as such, played a central role in the spiritual or religious experience of most cultures and the individuals living within them (Delaney 1998:9-64). This was especially true in the context of early Christianity, which inherited the Jewish dream beliefs, practices and traditions of the Old Testament, and reinterpreted many of these in the light of Christian morality (Ullman \& Zimmerman 1987:42). In both traditions, dreams were considered to be sources of inspiration, insight and prophecy from God (Delaney 1998:47). In the Bible itself, several references are made to the divine origin and nature of dreams (e.g. Gn 41:25, Ac 2:17, Nm 12:6 and Job 33:14). In addition to such direct commentary on the nature of dreams, both the Old and New Testaments contain several dream accounts. Most notable amongst these are the two dreams of Joseph (Gn 37 and Gn 40-41), Jacob's dream at Bethel (Gn 28), the Midianite soldier's dream (Jdg 7:13-14), Nebuchadnezzar's dreams (Dn 2 and Dn 4), Joseph's dream revealing Mary's immaculate conception (Mt $1: 20)$, the dream the three wise men shared warning them not to return to Herod after locating Jesus (Mt 2:12-13), and the dream of Pilate's wife (Mt 27:19).

\section{Dream beliefs of early church fathers and Christian scholars}

The importance assigned to dreams in the context of Christian spirituality was certainly not limited to biblical times. Dreams were generally considered to be quite an important phenomenon amongst the major Christian authors and church fathers of the first three centuries AD, including Clement, St. John Chrysostom and Augustine. According to both Clement and Augustine, dreams played a central role in revealing the relationship between man and God (Ullman \& Zimmerman 1987:42). Virtually all of them believed in the revelatory power of dreams. Dreams were seen to either portray or predict real events, as was reflected in the stories of the lives of several Christian saints and martyrs who had predictive dreams. In addition, it was believed that one could have meaningful encounters with God and His angels through dreams and that God spoke with mortals in dreams (Ullman \& Zimmerman 1987:42).

Augustine's views on dreams were especially influential and many of the most important treatises written from the 12th to the 15th centuries, such as Albertus Magnus's Summa de creaturus, Thomas Aquinas's Summa theologiae, and Jean de la Rochelle's Summa de anima which included references to dreams and were based on his theories (Kruger 1992:62).

Many of Augustine's views in turn, were influenced by the influential church father Tertullian, who lived in the early 3rd century (Delaney 1998:48) and made a simple but highly influential classification of dreams in his treatise De Anima. Dreams were divided into two categories, those dreams emanating from God, and those emanating from the Devil and his demons. Thus, although it was strongly believed that God spoke to his people through dreams, one had to be ever vigilant not to fall prey to dreams of the Devil that would tempt one into greater contact with evil. Sexual dreams, especially, fell under this category, and were seen to emanate from the Devil (Kruger 1992:44-45).

In the 5th century, Synesius of Cyrene wrote a book on dreams with a title that transliterates to 'Dreams take the soul to the superior region' (ed. Woods 1947:136-137) that was held in high esteem by the Eastern Church. He considered dreams to be highly significant and encouraged people to keep a dream journal. According to Synesius, dreams revealed bodily illnesses and cures, they gave people insights and solutions that escaped them when awake, and they could also serve as channel through which God could teach people, reveal His truth, and show them the future. He also believed that dreams were the product of the imagination, which he believed to lie halfway between reason and sensory experience (Kelsey 1974:142).

In contrast to the former perspectives, a rather negative view of dreams emerged from the writings of Jerome, a contemporary of Augustine, who was a gifted but troubled church father. After a very intense dream in which he was condemned and tortured for showing a greater interest in the classics of literature as opposed to biblical literature, his attitude towards dreams changed drastically. He especially warned against false dreams, and the possibility of demonic influence operating via dreams. He associated dreams with witchcraft, and considered any undue attention paid to dreams as superstitious (Ullman \& Zimmerman 1987:43).

The following centuries were characterised by stagnation in thinking on dreams as an increasingly negative view on dreams developed in Christian circles. Care was taken to encourage the belief that dreams were not from God and should therefore be ignored. As the church was seen as the ultimate authority due to it being considered as the keeper of the Word of God, it discouraged any reliance on dreams for divine insight and communication as being unnecessary. Certainly, any dream-related experiences or interpretations that fell outside the strict doctrines of the medieval church were looked upon with great suspicion and even condemnation (Ullman \& Zimmerman 1987:43).

This trend of ignoring dreams was reaffirmed in the late 12th century by Thomas of Froidmont who stressed the dangers in dreaming and warned strongly against a belief in dreams. He stated that those who placed their faith in dreams showed a lack of faith in God, and that undue attention focused on dreams threatens to lead us away from God, who should be the rightful object of our attention (Kruger 1992:83). This negative view of dreams was further reinforced in the 13th century by Thomas Aquinas, who could not reconcile the idea of people having free will with God speaking to them in dreams, thereby disavowing the possibility of any deeper significance to dreams (Ullman \& Zimmerman 1987:44).

The radical shift from viewing dreams as being (at least in some instances) of divine origin, and a prime channel of divine communication to that of seeing dreams as negative, deceptive or even downright evil seems to have had its 
inception with the reintroduction of Aristotle's major dream treatises, De sommniis, De somno et vigila and De divinatione per somnum. These works reintroduced into European Christian discourse the possibility that dreams were not divine in origin. As 13th century considerations of the dream became increasingly involved in Aristotelian thought, it departed significantly from late antique and earlier medieval dream theory (Kruger 1992:84-85).

However, full acceptance of Aristotelian positions was the exception rather than the rule as the denial of divine dreams clashed with biblical and patristic authorities, which did allow for the possibility of divine dreams. Most of the important scholars and writers on dreams during the middle ages allowed for exceptions to their general dream theories in conceding that divine dreams can and do occur in some instances. Yet, these concessions were usually followed by a warning that, as dreams come in so many varieties, it is very difficult for the average dreamer to distinguish between divine and useless dreams, and that the dreamer is best advised to be wary (Kruger 1992:84-85).

A generally negative view of dreams prevailed until the end of the middle ages when Calvin, who clarified Christian Protestant doctrine, upheld the notion that some dreams could be sent by God, and others by the Devil, yet offered no guidance as to how dreams should be interpreted (Delaney 1998:54). Somewhat later, Martin Luther expressed the belief that dreams could further self-knowledge by showing us our sins. Yet, ironically, he himself was so upset by his dreams that he prayed that God no longer speak to him through them (Ullman \& Zimmerman 1987:44).

\section{Contemporary Christian conceptions of dreams}

At present, there appears to be no clearly formulated doctrine or set of beliefs regarding the spiritual and religious significance of dreams within the context of especially Protestant-based Christianity. A review of contemporary literature related to dreams and religion seems to suggest that the religious significance and value that was attached to dreams amongst many biblical writers and early church fathers has virtually disappeared. This point is echoed by both Kelsey (1974:viii), who refers to the dream-related beliefs, theories and practices of the early church as 'put aside and practically forgotten in our own churches', and Delaney (1998:52-54) who states that to her knowledge, no major new movement in the understanding of dreams is to be found in the rest of the history of Christianity. Even as early as 1909, it has been stated in the Catholic Encyclopedia (Souvay 1909) that whilst modern theologians do continue to admit the possibility of supernatural dreams, in most cases it is seen as useless and illogical to attempt any such interpretation, and that dreams are now seldom heeded amongst civilised people.

It therefore appears that the role and value of dreams in the context of a person's relationship to God is at present undefined and unclear, and that the importance assigned to such dreams has dwindled significantly.

\section{Contributions of Sigmund Freud and Carl Jung}

Whilst intense scholarly interest in dreams was revived by the work and writing of Sigmund Freud and Carl Jung, their work was primarily based on a psychological perspective (Freud 1948; Jung 1974, 1984). However, their theories, especially those of Jung, have formed the basis of several studies that aimed to explore the connection between dreams and spirituality, and have come to heavily influence, perhaps even dominate, dream-based research to the extent that alternative perspectives, not conditioned by Jungian or Freudian notions, might have been inadvertently marginalised. As a possible result of this, direct inquiry (not conditioned by any psychological theory of dreams) into the beliefs and perceptions that the average individual holds about his or her dreams appears to be scant. More specifically, a thorough literature search indicated that there appears to be limited current research (which is not approached from a Freudian or Jungian perspective) with regard to the role that religion and spirituality play in the dreams of contemporary Christians, especially in the South African context. This situation prompted the researcher to conduct a study of contemporary dream-related beliefs and practices, which focused, amongst other aspects, on the relationship between religion and spirituality and contemporary dreams.

\section{Aim and methodology}

The aim of the study was to explore and describe current, local, nonscientific dream-related beliefs and practices amongst individuals via direct inquiry that is not conditioned by any existing dream theories. The study was conducted from a postmodern, social constructivist perspective and utilised a qualitative methodology.

\section{Sampling}

To this end, after obtaining the necessary permission, a purposive sample of 20 students was selected from the administrative database of the North-West University's Vaal-Triangle Campus. This database was chosen as this campus's student population is highly diverse with regard to culture, race, gender and age, and also as it is comprised of individuals from various different geographical areas.

Apart from the specific criteria of race and gender which required an equal number of participants to be selected from each category, the selection process was conducted in a randomised manner. Two letters were randomly and successively generated and matched, in order of selection, to the closest matching surname in the database in descending alphabetical order. This process continued until each purposive sampling category was completed.

Although not an initial selection criterion, all the participants described themselves as Christians. Denominations included Dutch Reformed (25\%), Roman Catholic (25\%), Old Apostolic (10\%), Methodist (5\%), Evangelic Reformed (5\%), Presbyterian (5\%), Lutheran (5\%), and Jehovah's Witness (5\%); $15 \%$ of participants did not belong to any particular 
denomination, even though they did describe themselves as Christians. The findings of the study in relation to the spiritual value and role of the participants' dreams would be relevant to a Christian spiritual context.

\section{Data collection}

The participants selected were then contacted telephonically, and provided with a brief overview of the aim and nature of the study, after which their willingness and permission to participate in the study were established. If permission was granted (which happened in all but one instance due to the student having relocated to a different geographical area) an appointment was set up for the interview. The location of the interviews was mostly the researcher's office, although he also visited several participants at their homes, depending on the preference of the particular participant.

Each participant was questioned about his or her dream beliefs via the use of a semistructured interview. To facilitate this process, nine themes were identified on the basis of a review of existing literature on cultural, religious, psychological, scientific, sociological and other dreamrelated beliefs, discourses and practices, and discerning the general themes, patterns, and salient categories that seemed to be commonly addressed in all of these discourses.

The following is a list of the most important themes that were explored in the interviews as well as examples of typical questions that were often asked of the participants in order to uncover their beliefs and practices related to that particular theme:

- The importance of dreams: typical questions included 'Are dreams important to you?' If 'yes', 'Why (not)?'

- Perceived origin and causes of dreams: typical questions included 'Where do you think dreams come from?' and 'What do you think causes dreams?'

- Perceived function and purpose of dreams: typical questions included 'What do you believe are the function of dreams?'; 'Why do we have dreams?'; and 'What role do they serve in our lives?'

- The extent and manner in which dreams influence the respondent's actions and decisions in daily life: typical questions included 'Do you ever base any actions or decisions on your dreams?'; 'Do your dreams ever affect the things you decide or do in your daily life?'; and 'Do you ever do or decide anything differently because of something that you dreamed about?'

- Unusual dream experiences and beliefs about these: typical questions included 'Have you ever had any unusual dream experiences?' and 'Can you tell me about these?'

- After such general questions, more specific questions were asked: 'Do you believe that dreams can show the future?'; 'Have you ever had such dreams?'; 'Do you believe that it is possible for deceased individuals or spiritual forces to make contact with you in a dream?'; and 'Have you ever had such a dream?'
- Strategies and methods of dream interpretation: typical questions included 'How do you make sense of your dreams?'; 'What do you do in order to interpret or understand your dreams?' and 'How do you decide what your dreams mean?'

- Sharing dreams with others, and reasons for doing so: typical questions included 'Do you ever share your dreams with others? Why? For what purpose?'; 'Do you ever go to others for assistance in making sense of your dreams?' In cases where the dreamer answered in the affirmative, the researcher questioned the participants about the approach taken by this individual, their background and influence on the participant.

- Origin and sources of respondent's dream beliefs and practices: typical questions included 'Where do your ideas on dreams come from?' and 'Where did you learn the things you know about dreams?'

- Open theme: this theme allowed for an open exploration of any other dream-related beliefs and practices the participant might have wanted to discuss that were not covered by the other themes. Questions included 'Are there any other things with regard to your dream life that we have not talked about? Is there anything else you can think of that might be relevant to talk about that we have not covered so far?' and 'What other things have you noticed about dreams that we have not talked about yet?'

Whilst most of these themes appear to have no direct bearing on spirituality, participants' responses often reflected spiritual and religious notions in relation to the majority of themes listed. This was especially the case with the following themes: the perceived origin and cause of dreams; the perceived purpose and function of dreams; unusual dream experiences and beliefs about such dreams; and the origin and sources of participants' dream beliefs and practices.

\section{Data analysis and interpretation}

The participants' comments were recorded during the course of the interviews. The data obtained from the interviews were then subject to qualitative content and discourse analysis on the basis of the nine general themes outlined previously. Colour coding was used to identify recurrent views, beliefs or comments within each major theme and findings from such themes were integrated into categories and themes. The synthesised data was then used to prepare descriptive accounts, identify key dimensions, and to map the range and diversity of responses within each category and theme. Where responses showed a significant difference in relation to cultural or gender group, these were noted. This entire process was repeated in that all the interview transcripts were subsequently examined, coded and categorised specifically in relation to religion and spirituality and contemporary dream beliefs, experiences and practices. The following section is devoted to a discussion of the categories and themes that emerged during this process.

\section{Research findings and discussion}

Nearly half of the participants expressed the belief that dreams could serve as channel for spiritual experiences and 
divine communication and that God could send warnings, messages or answers to prayers to a sleeping individual through dreams. Several participants claimed to have experienced this personally, as the following extracts from the qualitative interviews illustrate in the participants' own words:

'I also believe strongly that in some dreams God can actually use the dream to give me a sign or guidance on some issue.' (Participant 8)

'I often pray and then get answers to problems in dreams ... I think that dreams can come ... even from God.' (Participant 9)

'I think many other dreams are a message from God.' (Participant 14)

However, some of the participants who expressed this belief stated that they did not experience any of these phenomena personally, as is reflected in these excerpts:

'I have not had any spiritual experiences in my dreams, although I certainly believe that this is possible.' (Participant 10)

'Yes, I do believe that God can affect someone's dreams. But it has never happened to me.' (Participant 17)

'I have had spiritual experiences in my dreams in which I believe I received messages from God.' (Participant 6)

As the data from the interviews were coded and categorised based on the theme of religious significance of dreams, it emerged that the most strongly emphasised aspect of the religious significance of dreams was their perceived ability to serve as channel for divine communication and guidance in the form of prayers answered and messages given. Perhaps even more noteworthy was the finding that such messages were usually heeded and acted upon by the participants, as this excerpt from one of the interviews illustrates:

'In real life I then went ahead and actually did what the dream suggested and it worked out very well, the problem was resolved.' (Participant 6)

No significant cultural or gender differences were noted with regard to the aforementioned responses.

Overall, these responses from the interviews suggest that dreams still appear to bear notable religious and spiritual significance to some contemporary Christians, at least amongst the participant group, and possibly beyond these bounds.

Another noteworthy aspect that emerged from an overview of the findings pertains to the experience of divinely inspired dreams as opposed to dreams influenced by forces considered to be diabolical or otherwise evil. As was discussed earlier, in Christian discourses dreams were often rigidly classified as being either of divine or diabolical origin and dreamers were warned to discriminate carefully between these categories. A strong awareness of both kinds of dreams therefore existed in earlier Christian contexts. However, whereas the perception that God or some other elevated source or being was behind certain dreams seemed to have persisted amongst a significant percentage of the participants, the belief that the Devil or some other diabolical source might exert an influence on some dreams appears to be completely absent, as such notions were not expressed by any of the participants, except for a single reference by an African male participant who stated the belief that witchcraft might affect dreams:

'I think it is sometimes just the brain ... (but) I also think that witchcraft can sometimes affect your dreams.' (Participant 13)

This absence of the diabolical is conspicuous, especially in the light of the fact that almost half of the participants firmly believed in the potential divine origin of dreams. Whilst this tendency may or may not be reflective of the general population, it does raise some questions with regard to the extent and manner in which conceptions of the Devil might have changed amongst some contemporary Christians, which future research might seek to investigate in a more focused manner.

From a sociological perspective it has been argued that dream content not only expresses intrapsychic aspects of an individual, but that the general themes in the dreams of groups of individuals are reflective of broader cultural beliefs and conditions. In this regard the inner life of individuals as reflected in dreams appears to serve as mirror of outer cultural, societal en religious conditions (Bastide 1966:200 201; Ullman \& Zimmerman 1987:183-188). Any changes in cultural conceptions would therefore be reflected in similar changes in dreams (Ullman \& Zimmerman 1987:184-186). Compared to the emphasis placed on diabolical dreams by several Christian scholars in the past, it appears that there have been significant changes with regard to the perception, discourses and experience of the diabolical in dreams amongst the contemporary dreamers who participated in the study.

A small number of participants indicated that they did not see any religious or spiritual significance in dreams. However, these respondents nonetheless did feel that the deceased could speak to living relatives through dreams, or that dreams could predict the future, as this quote from one of the interviews indicates:

'I am a Catholic, but I don't think that that has an influence on how I see dreams either. I don't see dreams as religious.' (Participant 14)

The same participant said elsewhere in the interview:

'I dreamt on four different occasions that my husband died, and a week after my last dream he was shot and he died ... I think that [some] ... dreams are a message from God.'

These statements are clearly contradictory and suggest that the participant might not have reflected adequately on her initial response, or alternatively, that she might not have initially regarded the dream in a religious light. Whilst the exact reason for the participant's contradiction is not certain, it is clear that this participant's overt statement about her nonbelief in the religious value of dreams needs to be qualified.

A quarter of the participants indicated that they did not view dreams as possessing any spiritual, religious or psychic significance whatsoever, and did not express any other dream-related belief that could in any way be construed as spiritual. Four-fifths of these participants were White. 
These participants were also more likely than their African counterparts to regard such beliefs as superstitious. The following excerpts from the interviews illustrate these views in the participants' own words:

'I don't see dreams as being deep or spiritual things.' (Participant 2)

'I don't consider dreams important ... I don't think dreams have any real meaning or function, it is just a biological process.' (Participant 3)

'I don't believe that God or the ancestors can come to you in a dream. Many people in my culture believe it, but I don't. Dreams are just dreams ... I don't believe in that stuff about God speaking to people in dreams.' (Participant 16)

Two-thirds of the participants believed that the future could be revealed through dreams, and half of these participants cited personal examples of what they believed to be predictive dreams. African participants were about twice as likely as White participants to believe in and report predictive dreams. No clear gender differences were noted. The following extracts from the interviews serve to elucidate these contentions:

'Dreams tell us about the future, about what's going to happen. If you dream about something, some of it is going to happen.' (Participant 1)

'I think that bad dreams can often show you something bad in the future... I think the function of dreams is to show you what will happen in the future.' (Participant 4)

'I do think that dreams can tell you about what might happen in the future... I had a very vivid dream in which someone was dying from cancer. I saw the entire family standing around the sickbed. This was before I even found out about my grandmother's diagnosis. A month later things happened exactly as it did in the dream.' (Participant 8)

Although the participants did not always directly link such dream experiences with religion or spirituality, these findings are nonetheless significant with regard to such contexts, as the literature review undertaken for the purpose of the study revealed that in the context of historical Christianity, predictive dreams were generally regarded as being sent by God. In this regard Delaney (1998:47-48) states that virtually all of the early major Christian writers and church fathers not only believed in the possibility that God could reveal the future via dreams, but also often experienced such dreams personally.

All the comments related to the interview theme of dream experiences involving contact with some force beyond the individual's own psyche were coded and categorised. These comments revealed the somewhat surprising finding that nearly half of the participants believed that it was possible for a deceased individual or ancestor to make contact with a sleeping person through a dream, even though most participants did not experience this personally, as these quotes illustrate:

'I do believe that you can make contact with a deceased person in a dream.' (Participant 8)

'I do think that you could have contact in a dream with the soul of someone who is already dead, although I did not have any such dreams ...' (Participant 5)

'I definitely believe that you can make contact with the spirits of the deceased in your dreams ... I have never had any dreams in which my ancestors contacted me.' (Participant 1)
'I've never had any dreams in which dead people came to me in a dream, but I do think this might be possible.' (Participant 17)

However, 20\% of the participants stated that they personally had an experience in which they believed that a deceased individual, usually a close relative or an ancestor came to them in a dream; for example:

'One night, a few weeks after my grandmother's death, I had a dream in which my grandmother came to me and told me she was OK...' (Participant 8)

'At one time I was hearing voices in my dreams. I did not know who or what it was, but it was very real and persistent. Eventually my parents gave me some traditional herbs to drink ... and the voices disappeared.' (Participant 9)

'A while ago I felt someone touch my shoulder while I was dreaming. This felt extremely real ... I had the distinct feeling that it was my aunt, who passed away a year ago.' (Participant 6)

'... and my father appeared to me in my dream several times and he told me...' (Participant 15)

'I have also had a dream in which my father's father came to me in a dream and gave me a message that related to my own father.' (Participant 13)

Male and African participants were twice as likely to express this belief as the female or the White participants. The perceived functions of such contact included bringing reassurance, delivering a message that was of importance to someone still living, including commenting on the behaviour of the living, communicating a specific need or wish on the part of the deceased, and preparing the dreamer to accept the impending death of someone.

The belief that ancestors are able to visit a living relative in the dream state is strongly articulated in the vast majority of African dream-related discourses (Bührmann 1978:106; Schweitzer 1996:75). In fact, in many African cultures dreams are spiritually regarded as a primary link to the spirits of deceased ancestors, which are referred to by terms such as midzimu, amakhosi, idlozi and ithongo (Mbiti 1997:514-515; Jedrej \& Shaw 1992:6). As several of the participants cited earlier are African, it seems probable that their beliefs in this regard have been influenced by traditional African discourses on the matter.

Yet, not only African, but also about a fifth of the White participants expressed this belief, and in both instances claimed it as personal experience that deceased individuals have contacted them via a dream. This concept does not generally appear to be clearly articulated in a biblical context, however, yet it still bears potential religious significance.

Furthermore, although such experiences were not always discussed in an overtly spiritual context, they do have relevance in this regard in that such experiences serve to viscerally (albeit subjectively) attest to the fact that there is an afterlife and that the soul of a person endures despite the death of the physical body. Such experiences therefore have the potential to greatly strengthen an individual's faith, as it is based on personally felt experience, as opposed to the mere adoption of an intellectual belief. Of course it is 
impossible to prove in any scientifically accepted manner whether such contacts do indeed objectively represent contact with the actual consciousness or soul of the deceased or not. Pursuing such an aim would prove fruitless, and it is perhaps more useful to focus on the intense subjective reality and consequent positive impact on an individual's faith and sense of well-being that such experiences sometimes elicit.

It could further be argued that coming to terms with the loss of a loved one is essentially a spiritual task, as it involves questions about the meaning of life and death, and the reality of an afterlife. Several participants indicated that their dreams brought them substantial relief and comfort in dealing with the loss of a loved one, as the following excerpt shows:

'One night, a few weeks after my grandmother's death, I had a dream in which my grandmother came to me and told me she was OK... she also told me that she was OK and happy where she was now. This dream brought me a great deal of assurance... I am not absolutely sure whether the dream was a real contact with my grandmother or not. I think it was ...' (Participant 8)

This suggests that dreams could prove very valuable in assisting at least some individuals with the resolution of grief over a deceased loved one. The viscerally and intensely felt reality of such experiences served to confirm and strengthen these individuals' sense of the continuity of the soul and the existence of a benevolent afterlife in a way that mere intellectual belief or persuasion might not have accomplished. If pastoral counsellors are aware of this they might enquire about an individual's dreams following the death of a significant other, and through discussion and validation of this dream experience, support the client in working through the grieving process. The pastoral counsellor could serve as an audience for the full recounting of the dream narrative, thereby adding subjective weight and importance to it. In the interactive process in which the individual recounts his or her dream to the counsellor who listens and offers questions or comments, positive meaning can be generated around the dream experience, thereby reinforcing the therapeutic effects of the dream.

In addition, the research findings suggested that this strategy might in certain instances be effectively expanded in that an individual might be encouraged to share such a dream (that brought him or her comfort) with relatives or other individuals who might also be affected by the loss, thereby assisting these individuals in dealing with their own grief, as this excerpt indicates:

'This dream ... helped me cope much better with the grief over my grandmother's death. I even told the dream to my father and it helped him too ... we both felt better.' (Participant 8)

The importance of obtaining assistance in interpreting dreams has been strongly emphasised in the context of historical Christianity, and accordingly religious authorities often provided extensive commentaries and explicit guidelines for Christians on how dreams should be viewed, understood and interpreted (Ullman \& Zimmerman 1987:37; Husser 1999:93;
Noegel 2001:54-55). However, the interviews indicate that none of the participants ever sought or received any form of dream-related guidance or advice from any kind of religious authority figure. Given the fact that most of the respondents viewed their dreams as being of direct spiritual or religious significance, and that many of them consciously sought to understand and interpret their dreams in a religious light, this suggests that there might be notable value in addressing the topic of dreams and spirituality in the context of religious sermons or similar forums.

One of the central themes used to guide the interviewing process concerned the consciously perceived source of the participants' personal dream-related beliefs and practices. Participants were asked where their personal beliefs about dreams originated. From the analysis of the interviews it appeared that while the majority of participants used in this study had no or limited conscious awareness of the origin of their dream-related beliefs and practices, three African participants stated explicitly that their culture or religion played no role in affecting what they believed about dreams, as these excerpts indicate:

'My Catholic religion plays no role in how I see dreams. I don't see any links between my religion and my dreams.' (Participant 5)

'I am Catholic, but I don't think that that has an influence on how I see dreams ... I don't see dreams as religious.' (Participant 14)

'I don't think that my religion affects what I believe about dreams at all.' (Participant 16)

However, a third of the participants (the vast majority of them African) indicated that cultural and religious beliefs and practices had a direct influence on their beliefs about dreams. Several African participants also specifically mentioned that as far as dreams were concerned, they seek to integrate their Christian beliefs with elements of their traditional African cultural and spiritual heritage, as these excerpts show:

'I would say that $80 \%$ of what I believe about dreams comes from my grandmother [traditional Tswana beliefs] and about 20\% from my Christian religion.' (Participant 1 )

'In my family there is still a lot of traditional beliefs, and also Christian beliefs [about dreams].' (Participant 4)

'I myself am a Christian, although I also consider some aspects of my traditional [Northern Sotho] heritage to be very important. I see no conflict between our traditional beliefs and Christianity - they both have the same goal.' (Participant 9)

'But my religion also plays a role. I have always tried to link my Christianity and my Sesotho beliefs, to bring them together. So I believe that the ancestors can speak to me in a dream, but I also believe that God can speak to me in a dream.' (Participant 15)

'But I'd say that maybe both my traditional culture [Sesotho] and my religion [Jehova's witness] play some role [in how the participant views dreams].' (Participant 20)

These statements seem to echo Mbiti's (1997:511) finding that 'it is clear that the coming of Christianity has not erased this African dream culture'. He goes on to say there is great potential for inter-religious dialogue between Christianity and African religion if the dialogue already taking place on the plane of dreams can be developed. 


\section{Conclusion}

In this article it was indicated that there is a marked lack of clarity amongst existing dream-related research as to what roles, if any, dreams play in the personal religious experience of the average South African Christian today. From the study that was conducted to address this issue, it was concluded that even though some participants appeared to view their dreams as being devoid of any spiritual significance, dreams still hold substantial religious and spiritual significance to at least some individuals, and that such dreams often serve as source of inspiration, insight, guidance, as well as feedback on decisions and ways of living. Specifically, some participants stated that they often look to their dreams for insight, and even base actions and decisions on certain dreams. It was also indicated that dreams sometimes constituted an important natural resource in coming to terms with bereavement. At least in some instances therefore, dreams continue to play a significant role in the spiritual experience of Christians, and as such have potential value in deepening individuals' experiences of their own sense of spiritual awareness and connection.

In summary then, it appears that God is indeed still seen to speak to his followers in dreams, and that the insights, messages, guidance and general nature of such dreams sometimes exert a significant and positive impact on the lives and spiritual experience of at least some individuals.

However, the findings also suggest that many Christians appear to be given little or no external guidance on ways to use their dreams in a spiritual sense, as was indicated by the finding that not a single participant ever sought or received advice or guidance in relation to their dreams from any kind of religious or spiritual authority. Kelsey $(1974: 1,6)$ echoes a similar sentiment when he says that in Western Christian society today there is no group, practically no voice at all that would encourage the average Christian to understand his or her dreams as a source of religious insight into life. And yet, the Christian interpretation of dreams is an ancient, long held, and carefully considered religious practice, and therefore deserves to be reviewed and re-evaluated. Perhaps the time is ripe to revivify this aspect of Christianity; to re-imbue dreams with a sense of the spiritual - allowing people to reclaim a potentially powerful channel of spiritual experience, which now seems lost to many. As such, it might prove useful and valuable not only for Christian individuals in general, but also for people in positions of religious authority as well as counsellors and therapists working within a Christian context to pay more attention to the religious and spiritual elements of dreams, and to thereby reassume roles of guidance in this important context. However, the practical realisation of this goal is complicated by the fact that several pertinent questions are still left unanswered: how can a dreamer be certain that a given dream does indeed have a spiritual significance? Even worse, could some dreams be influenced by internal or external factors that work against our highest interests? If so, how would a dreamer distinguish between a genuinely spiritual dream and a dream that might derive from other, perhaps even potentially harmful inner or outer sources? Would acting on a seemingly spiritual dream not entail a degree of risk, in the case that the dreamer was mistaken as to either the origin or the interpretation of the dream? These questions transcend the realms accessible to social research, and as such, cannot be conclusively answered on this basis. Certainly, outright unquestioning acceptance of any dream as spiritual would appear ill-advised as it would be virtually impossible to conclusively prove that a given subjective dream experience does indeed have a spiritual origin or message. Conversely, ignoring dreams altogether for fear of misinterpreting them might constitute a rejection of a valid and potentially richly meaningful aspect of a dreamer's spiritual experience. As such, a middle ground is called for in which the potential for dreams to bear spiritual significance is acknowledged in a spiritually responsible and discerning manner. To these ends, the following pragmatic guidelines are offered as a starting point in the endeavor of translating the findings of this study into practical application: firstly, by raising our awareness of the possibility that dreams could at times provide meaningful spiritual insight and experiences, we would likely enhance the possibility that we might receive, or at the very least, notice and recall such dreams. Secondly, dreamers might take note of dreams that subjectively appear to have potential spiritual significance, and could ideally record such dreams in a journal or diary. Thirdly, after examining the dream on a literal and a symbolic level in relation to their own lives, an initial, tentative interpretation can be formulated. To guard against erroneous interpretations, it could be suggested that dreamers, instead of accepting (and acting upon) the apparent message of the dream outright, first weigh the perceived message or experience of the dream against their spiritual values and ideals as well as against their current life contexts. (Nightmares and other dreams that elicit significant negative emotions are unlikely to be considered spiritual in the first place, and should best be discussed with a professional individual who has been trained in working with such dreams). Should there be any uncertainty as to the spiritual validity or meaning of the dream, the dreamer could pursue strategies such as waiting for a follow-up dream to clarify the first, praying for (additional) guidance on the matter, or discussing the dream with a trusted spiritual advisor. Dreams which contain elements that run counter to the dreamer's spiritual values should be questioned, and might likely not be spiritually valid (yet it is highly unlikely that such dreams would be experienced as spiritual to begin with). Conversely, as a fourth step, should the message of the dream be in accord with the dreamer's waking spiritual values and make constructive sense in the context of the dreamer's life situation, the dreamer could consider accepting the dream experience as potentially valid. If it seems to be indicated, the dreamer could then take a well-considered first action based on what his or her dream appears to have suggested, and then note the effect and consequences of this action. Should this be spiritually and otherwise constructive, and still in keeping with the dreamer's spiritual values, a second step can be taken, and so on. In this manner a dreamer might work to open and cultivate a potentially profound and deeply meaningful channel of spiritual experience, insight 
and guidance in a considered, balanced, and spiritually responsible manner.

\section{Acknowledgements Competing interests}

The author declares that he has no financial or personal relationship(s) which may have inappropriately influenced him in writing this article.

\section{References}

Bastide, R., 1966, 'The sociology of the dream', in G.E. von Grunebaum \& R. Callois (eds.), The dream and human societies, pp. 200-214, University of California Press, Los Angeles, CA.

Bührmann, M.V., 1978, 'The Xhosa healers of Sothern Africa', Journal of analytical psychology 27, 41-57.

Bulkeley, K., 2009, 'Mystical dreaming: Patterns in form, content, and meaning', Dreaming 19, 30-41. http://dx.doi.org/10.1037/a0014788

Casto, K.L., 1995, 'Contemporary spiritual dream reports: Their content and significance', PhD thesis, Department of Psychology, Saybrook Institute.

Delaney, G., 1998, All about dreams, Harper Collins Publishers, San Francisco, CA.

Eliade, M., 1964, Shamanism: Archaic techniques of ecstasy, Princeton University Press, Princeton, NJ.

Freud, S., 1948, The interpretation of dreams, George Allen \& Unwin Ltd, London.

Hall, D.H., 1997, 'Beliefs about dreams and their relationship to gender and personality', The Sciences of engineering 57 (7-B), 4766.
Husser, J.M., 1999, Dreams and dream narratives in the Biblical world, Sheffield Academic Press, Sheffield.

Jedrej, M.C. \& Shaw, R., 1992, Dreaming, religion and society in Africa, E.J. Brill, Leiden. Jung, C.G., 1974, Dreams, Routledge, London.

Jung, C.G., 1984, Dream analysis, Princeton University Press, New Jersey, NJ.

Kelsey, M.T., 1974, God, dreams, and revelation, Augsburg Publishing, Minneapolis, MN.

Kripal, J.J., 1995, Kali's child: The mystical and the erotic in the life and teachings of Ramakrishna, University of Chicago press, Chicago, IL.

Kripal, J.J., 2001, 'Re-membering a presence of mythological proportions: Psychoanalysis and Hinduism', in D. Jonte-Pace \& W.B. Parsons (eds.), Religion and psychology: Mapping the terrain, pp. 254-278, Routledge, London.

Kruger, S.F., 1992, Dreaming in the middle ages, Cambridge University Press, Cambridge. http://dx.doi.org/10.1017/CBO9780511518737

Mbiti, J., 1997, 'Dreams as a point of theological dialogue between Christianity and African religion', Missionalia 24(4), 511-522.

Noegel, S., 2001, 'Dreams and dream interpreters in Mesopotamia and in the Hebrew Bible (Old Testament)', in K. Bulkeley (ed.), Dreams: A reader on the religious, cultural, and psychological dimensions of dreaming, pp. 45-62, Palgrave, New York, NY

Schweitzer, R., 1996, 'A phenomenological study of dream interpretation among the Xhosa speaking people in rural South Africa', Journal of phenomenological psychology 27, 72-95. http://dx.doi.org/10.1163/156916296X00041

Souvay, C., 1909, 'Interpretation of Dreams', in The Catholic Encyclopaedia, Robert Appleton Company, New York, viewed June 24, 2010 from http://www. newadvent.org/cathen/05154a.htm

Ullman, M. \& Zimmerman, N., 1987, Working with dreams, The Aquarian Press, Northamptonshire.

Woods, R.L. (ed.), 1947, The world of dreams, Random House, New York, NY. 